\title{
Defining comprehensive models of care for NAFLD
}

Jeffrey V. Lazarus ${ }^{1,2+}$, Quentin M. Anstee ${ }^{3,4}$, Hannes Hagström ${ }^{5}$, Kenneth Cusi ${ }^{6}$, Helena Cortez-Pinto ${ }^{7}$, Henry E. Mark2 ${ }^{2}$ Michael Roden $8,9,10$, Emmanuel A. Tsochatzis ${ }^{11,12}$, Vincent Wai-Sun Wong ${ }^{13}$, Zobair M. Younossi ${ }^{14}$, Shira Zelber-Sagi ${ }^{15,16}$, Manuel Romero-Gómez ${ }^{17}$, Jörn M. Schattenberg ${ }^{18}$

1. Barcelona Institute for Global Health (ISGlobal), Hospital Clínic, University of Barcelona, Barcelona, Spain.

2. EASL International Liver Foundation, Geneva, Switzerland.

3. Translational \& Clinical Research Institute, Faculty of Medical Sciences, Newcastle University, Newcastle upon Tyne, United Kingdom.

4. The Liver Unit \& NIHR Biomedical Research Centre, The Newcastle upon Tyne Hospitals NHS Foundation Trust, Newcastle upon Tyne, United Kingdom.

5. Karolinska Institute, Stockholm, Sweden.

6. Division of Endocrinology, Diabetes \& Metabolism, Department of Medicine, University of Florida, Florida, United States.

7. Clínica Universitária de Gastrenterologia, Laboratório de Nutrição, Faculdade de Medicina, Universidade de Lisboa, Portugal.

8. Division of Endocrinology and Diabetology, Medical Faculty, Heinrich Heine University, Düsseldorf, Germany.

9. Institute for Clinical Diabetology, German Diabetes Center (DDZ), Leibniz Center for Diabetes Research at Heinrich-Heine University, Düsseldorf, Germany.

10. German Center for Diabetes Research, Partner Düsseldorf, Germany.

11. University College London Institute for Liver and Digestive Health, Royal Free Hospital, London, United Kingdom.

12. Sheila Sherlock Liver Centre, Royal Free Hospital, London, United Kingdom.

13. Department of Medicine and Therapeutics, The Chinese University of Hong Kong, Hong Kong.

14. Center for Liver Diseases, Department of Medicine, Inova Fairfax Medical Campus, Falls Church, Virginia, United States.

15. University of Haifa, Faculty of Social Welfare and Health Sciences, School of Public Health, Mount Carmel, Haifa, Israel.

16. Department of Gastroenterology, Tel-Aviv Medical Centre, Tel-Aviv, Israel.

17. UCM Digestive Diseases, CIBEREHD and IBIS, Virgen del Rocío University Hospital, University of Seville, Seville, Spain.

18. Metabolic Liver Research Program, I. Department of Medicine, University Medical Centre Mainz, Mainz, Germany.

†email: Jeffrey.Lazarus@isglobal.org

There is a need for effective models of care for patients with nonalcoholic fatty liver disease (NAFLD). In this Expert Recommendation, Lazarus et al. discuss seven examples of comprehensive NAFLD models of care, and produce eight recommendations aimed at policymakers and practitioners.

\section{Abstract}

Nonalcoholic fatty liver disease (NAFLD) is now the leading cause of chronic liver disease globally. Despite the increased demand placed on healthcare systems, little attention has been given to the 
design and implementation of efficient and effective models of care for patients with NAFLD. In many healthcare settings, no formal pathways exist and where pathways are in place, they are often not standardized according to good practices. We systematically searched the peer-reviewed literature with the aim of identifying published examples of comprehensive models of care that answered four key questions: what services are provided; where are they provided; who is offering them; and how are they coordinated and integrated within healthcare systems. We identified seven models of care and synthesized the findings into eight recommendations nested within the 'what, where, who and how' of care models. These recommendations, aimed at policymakers and practitioners designing and implementing models of care, can help to address the increasing need for the provision of good practice care for patients with NAFLD. 
Nonalcoholic fatty liver disease (NAFLD) is a highly prevalent and potentially progressive illness ${ }^{1,2}$ and the leading cause of chronic liver disease worldwide. ${ }^{3}$ Left untreated, NAFL (steatosis) can evolve to nonalcoholic steatohepatitis (NASH), with increasing hepatic fibrosis leading eventually to cirrhosis, liver cancer, end-stage liver disease and death. ${ }^{3,4}$ NAFLD is estimated to affect $25 \%$ of the global population, with NASH affecting up to $20 \%$ of people with NAFLD; ${ }^{2,5,6}$ however, reliable epidemiological estimates are scarce.

NAFLD is part of a multisystem disease that affects extrahepatic organs and is associated with other diseases (Box 1). ${ }^{7-9}$ The leading cause of death in patients with NAFLD is cardiovascular disease (CVD), and other common causes of death include extrahepatic malignancies, type 2 diabetes mellitus (T2DM), chronic kidney disease, and liver-related complications. ${ }^{7,8,10-13}$ NAFLD is associated with substantial economic losse ${ }^{14}$ and healthcare costs ${ }^{14-16}$, and it also contributes to impaired health-related quality of life. ${ }^{17}$

There are numerous gaps in the current clinical management of NAFLD. Owing to its comorbid nature, patients with NAFLD will likely benefit from multidisciplinary care ${ }^{18}$; however, awareness of the disease among the general population and non-liver specialist healthcare providers is low. ${ }^{19}$ The grading, staging and definitive diagnosis of NASH relies on liver biopsy, an invasive procedure not practical to conduct in primary care. ${ }^{20,21}$ Coupled with the lack of overt symptoms, this commonly leads to a clinically relevant delay in the establishment of a diagnosis, with many patients diagnosed in an advanced stage, which is associated with a less favourable prognosis. There are no approved pharmacological treatments specifically for $\mathrm{NASH}^{22}$; however, there is a large body of evidence for the effectiveness of non-pharmacological treatments that can halt the progression of the disease or even cause remission in the early stages. ${ }^{23-25}$

There are several regional guidelines on the clinical management of NAFLD, including joint guidance from the European Association for the Study of the Liver (EASL), European Association for the Study of Diabetes (EASD) and the European Association for the Study of Obesity (EASO) ${ }^{26}$, and from the American Association for the Study of Liver Diseases (AASLD). ${ }^{27}$ However, in many healthcare settings no written pathway exists for identifying patients and linking them to care, ${ }^{28}$ and where pathways are in place, they are often not standardized according to best practices. Furthermore, there is little information about the services that are provided to patients along the NAFLD disease spectrum and how services are coordinated and integrated within health care systems. As a result, health outcomes for patients with NAFLD vary widely, both within and between healthcare settings.

To improve outcomes for people with NAFLD it is imperative to further our understanding of how to effectively and efficiently provide care that is centred around each individual patient's needs. A model of care $(\mathrm{MOC})$ is a setting-specific framework that outlines how patients are managed along the cascade of care.$^{29}$ Establishing multidisciplinary MOCs tailored to a patient's position on the disease spectrum should be a priority for policymakers and healthcare providers. Similar work has proven successful in improving care for patients with hepatitis $C^{29}$

In this Expert Recommendation, we draw on published examples of NAFLD MOCs and the opinions of experts in the field to develop a series of recommendation for policymakers, healthcare providers and other stakeholders looking to improve the clinical management of this condition in years to come.

\section{[H1] Models of care for NAFLD and NASH}

To guide the development of our recommendations we conducted a literature search to identify published examples of comprehensive NAFLD MOCs that address four key questions: what services 
are provided, where are the services provided, who is providing the services and how are the services integrated ${ }^{30}$ (see Review Criteria and Supplementary Information).

We identified seven comprehensive MOCs (Table 1) and analysed their component parts, making a synthesis across all models. We supplement this with expert opinions to develop a set of eight recommendations for healthcare providers and policymakers seeking to design and implement effective NAFLD care models. We clustered the recommendations under the headings: what, where, who and how (Box 2). Below we discuss each recommendation, drawing on the seven published examples and supporting this with a summary of the wider literature.

\section{[H1] What services do NAFLD patients require?}

\section{[H2] 1. Establish care pathways tailored to patient needs}

The intensity of care required for a patient with NAFLD depends on the disease stage. An estimated $5 \%$ of patients with NAFLD experience advanced hepatic fibrosis, ${ }^{31}$ with this group having the highest overall and liver-related mortality. These patients, including those with oesophageal varices and hepatocellular carcinoma, require expert management involving hepatologists and gastroenterologists, whereas patients with lesser degrees of fibrosis can often be managed in primary care..$^{32}$ Obesity, $T 2 D M$ and $C V D^{7,8,33}$ are common in patients with NAFLD, and as such, care pathways for NAFLD need to account for the presence of multiple comorbid conditions and facilitate the provision of a comprehensive package of care based on each individual patient's needs.

The European Pathway Association define a care pathway as "a complex intervention for the mutual decision making and organisation of care processes for a well-defined group of patients during a well-defined period." ${ }^{34}$ For NAFLD, the first step in such a pathway is the risk stratification of patients, enabling a determination of their disease stage and the level and intensity of care required. This stratification not only ensures that patients in need of specialist care can be linked to services, but also avoids the utilization of resources on unnecessary referrals.

Four of the seven MOCs we identified provided a detailed summary of their care pathways and approach to risk stratification (Table 2). In Nottingham, UK, a community pathway was developed for the identification and risk stratification of liver diseases, including NAFLD, with clearly defined criteria for referring patients to secondary care for further assessment. ${ }^{35}$ In both Oxfordshire, UK, and Camden \& Islington, UK, care pathways were developed through collaborative processes between liver specialists and local clinical commissioning groups, with the aim of identifying and referring patients at high risk of advanced liver disease to specialist clinics. ${ }^{36,37}$ In North East England, where Newcastle upon Tyne Hospitals NHS Foundation Trust (NUTH) is located, a defined referral pathway for patients with abnormal liver blood tests has been in place since 2014, including assessment with Fibrosis-4 (FIB-4) score or NAFLD fibrosis score (NFS) prior to secondary care referral. ${ }^{38}$ However, a recent audit showed that only $16 \%$ of patients referred to secondary care had FIB-4 or NFS completed prior to clinic referral, ${ }^{39}$ highlighting the challenges of implementing such pathways at scale.

We identified several additional examples of care pathways that have been implemented in routine practise. In Calgary, Canada, a NAFLD care pathway was jointly developed by hepatologists, radiologists and primary care physicians to facilitate stratification of patients with NAFLD risk factors in primary care, and to guide referrals to specialist hepatology services. ${ }^{40}$ In Dundee, UK, an automated investigation algorithm termed 'intelligent liver function testing (iLFT)' has been 
developed to optimize the investigation of abnormal liver function tests in a cost-effective manner and to guide referral and management decisions. ${ }^{41}$

Clear pathways that direct patients to the appropriate clinical services are essential for managing the burden of NAFLD, providing clarity for both patients and healthcare providers, while ensuring the efficient and effective utilization of resources. The primary aim of these pathways is to identify patients and guide clinical decisions about the services they require. The local and national context, including health system structures and funding and reimbursement systems, need to be considered when developing such care pathways. The cited examples also highlight the need for collaboration across disciplines and between primary and secondary care throughout the design and implementation process. Moving forward, stakeholders should prioritize developing the evidence base around effective care pathways, including assessing clinical and patient-reported outcomes, such as health-related quality of life, ${ }^{42,43}$ and the cost-effectiveness of different approaches. This process can start with the evaluation of existing practices.

\section{[H2] 2. Develop guidance on screening and testing with non-invasive tests}

Diagnosing NAFLD remains an enduring challenge, with diagnoses often incidental following the identification of abnormal liver enzymes or steatosis on imaging. ${ }^{44} \mathrm{~A}$ lack of consensus on whether to screen for NAFLD in high-risk patients further complicates this issue, with national guidelines differing on these points. Joint guidance developed by EASL, EASD and EASO recommends screening for NAFLD in people with obesity, metabolic syndrome and in particular T2DM. ${ }^{26}$ Guidelines from the Asia-Pacific Working Party on NAFLD note that screening should be considered in high-risk populations including those with T2DM and obesity. ${ }^{45}$ The American Diabetes Association has recommend screening for NASH and advanced fibrosis in patients with elevated liver function tests or hepatic steatosis on ultrasound. ${ }^{46}$ In contrast, AASLD does not recommend systematic screening in high-risk groups-namely people living with diabetes or obesity-attending primary care, diabetes or obesity clinics, citing a lack of evidence on the cost-effectiveness of this approach. ${ }^{27}$

Liver biopsy remains the reference standard diagnostic for determining NASH and the stage of hepatic fibrosis, but the procedure is resource intensive and impractical in primary care and many secondary care settings. The advent of high negative predictive value non-invasive tests (NITs) targeting the detection of advanced liver fibrosis (but not specifically NASH) has promoted the development and implementation of care pathway innovations such as those outlined in Table 2. Fibrosis stage is the best surrogate for long-term patient outcome, and therefore the ability to rule out advanced fibrosis is highly valuable in clinical settings. ${ }^{47}$

NITs fall into two complementary groups: surrogate scores and ratios based on indirect and/or direct serum biomarkers-such as aspartate aminotransferase (AST) to alanine aminotransferase (ALT) ratio and Fibrosis-4 score (FIB-4)-and liver stiffness measured by ultrasound or magnetic resonance-based elastography techniques. ${ }^{48}$ The performance of these NITs is strongly influenced by pre-test probability, with the negative predictive value of NITs for predicting advanced fibrosis being generally high in primary care settings where there is a low population prevalence of advanced disease, whereas the positive predictive value is lower. ${ }^{49,50}$ However, there is growing evidence that combinations of NITs used in sequential algorithms can help to detect advanced fibrosis. ${ }^{51-55}$

All of the care pathways we identified that utilize NITs for the risk stratification of patients follow a sequential approach that relies on the high negative predictive value of the tests to rule out the presence of advanced fibrosis. The optimal choice of NIT and the corresponding cut-offs are being explored in a number of prospective studies to determine an acceptable balance between healthcare spending and favourable clinical outcome. Within these discussions, important 
consideration is being given to the need for specific cut-offs in sub-populations, including patients with diabetes. ${ }^{56}$

The NITs used in four models, their cuts-offs and the management decisions based on the test results are summarized in Table 2 In the absence of a single optimum biomarker, each model represents an exemplar of how this common challenge is addressed and the inherent compromises due to the trade-off between diagnostic performance and the feasibility of implementation.

The Nottinghamshire care pathway screens patients in primary care, referring those at high risk of advanced liver disease to a secondary care facility for further assessment by transient elastography. Of 813 patients referred to the transient elastography clinic, $812(99.9 \%)$ understood the reason for their appointment and 731 (89.9\%) knew what to expect during their visit, and 804 (98.9\%) said they would recommend the service to others. ${ }^{35}$ The North East England pathway uses the FIB-4 score followed by transient elastography in a two-step process, with clearly defined age-specific cut-offs to guide decisions about the need for further assessments and how patients should be managed in both primary and secondary care settings. ${ }^{38,39}$

In the Camden \& Islington pathway, patients are first screened using FIB-4 to increase pre-test probability. Based on the results, patients are either managed in primary care, referred to a specialist clinic or undergo further assessment with the enhanced liver fibrosis (ELF) test. An evaluation of this pathway between March 2014 and May 2015 showed that it resulted in the detection of five times more cases of advanced fibrosis and cirrhosis while reducing unnecessary secondary care referrals by $81 \%$, although the number of cases missed could not be determined. ${ }^{36}$

The Nottingham, Camden \& Islington and North East England pathways recommend re-assessing for advanced fibrosis risk in patients not meeting the criteria for a specialist referral within 3-5 years. ${ }^{35,36,38}$ Repeat assessment with FIB-4 within 5 years has been shown to improve the identification of patients at risk of severe liver disease; however, the sensitivity is relatively low, ${ }^{57}$ which points to the need for improved, low cost and easily implementable assessment tools for use in primary care settings.

The Oxfordshire pathway utilised the NFS to screen patients in primary care prior to referral to the specialist hepatology clinic. Patients with indeterminate $(\geq-1.445-<0.676)$ or high-risk scores $(\geq 0.676)$ were referred while those with low scores remained in primary care. For patients referred to the specialist clinic without prior risk stratification, the assessment was conducted at the hepatology clinic. Within the hepatology clinic, patients with an indeterminate NFS score were assessed by FIB-4, NFS and transient elastography (FibroScan, Echosens). ${ }^{37}$ This pathway was subsequently updated in November 2017, incorporating the ELF test in place of the NFS. ${ }^{58}$

Patients referred to a NAFLD clinic in Birmingham, UK, undergo a full liver aetiology screen and an abdominal ultrasound scan. Patients with a diagnosis of NAFLD subsequently received transient elastography (FibroScan) and where indicated an ultrasound-guided liver biopsy. ${ }^{59}$

The Calgary pathway employs shear wave elastography (SWE) to assess patients with probable NAFLD. Of 2,084 patients with suspected NAFLD, 1,958 (94\%) received a confirmed diagnosis by ultrasound. Of the patients with NAFLD, 1,791 had SWE $<8.0 \mathrm{kPa}(91.5 \%), 167(3.4 \%)$ had $\mathrm{kPa}>8.0$ and were referred to a hepatologist, and a further 100 (5.1\%) patients with indeterminate SWE results were also referred. ${ }^{40}$

NITs provide opportunities to design and implement risk stratification strategies that ensure patients are linked with the expertise and services they require. Importantly, care pathways utilizing NITs 
have been shown to be cost-effective, especially when employed in a step-wise algorithm, lowering healthcare cost by reducing unnecessary specialist care referrals while ensuring patients are linked with the services they require ${ }^{60-62}$ Clear guidance on which test should be used to assess patients at different points of the health system, which population groups should be specifically targeted, and how patients progress through the care pathway based on test results are critical considerations for the development and implementation of effective and efficient MOCs. We recommend the routine testing of patients with T2DM using NITs to detect the presence of advanced fibrosis. This welldefined population group is known to have a high prevalence of NAFLD, and ensuring timely diagnosis and linkages to care holds promise for improving patient outcomes.

The care pathways we identified differ substantially in terms of their referral methods and processes. The availability of different NITs and the choices for their inclusion within pathways will vary among settings and might not necessarily reflect the optimum testing strategies, but rather a compromise based on what can be implemented in a particular setting at the time of initial presentation. When developing pathways and selecting which NITs to incorporate the local context, including availability of tools, must be considered. Systems also need to be put in place to facilitate the implementation of the agreed pathways: automating the calculation of NIT scores (for example, FIB-4) and providing clear guidance to care providers on what actions should be taken are simple yet effective ways to support the efficient delivery of these pathways. Primary care providers, who have a central role in identifying and referring patients with NAFLD requiring specialist care, have competing priorities and limited resources, ${ }^{63,64}$ and they should be engaged and involved early in the guideline development process, as should patient organisation representatives.

\section{[H2] 3. Develop guidance on treatment strategies related to disease stage}

Management strategies for patients with NAFLD need to be tailored to the disease stage. The management of patients with NASH and advanced fibrosis is an enduring challenge given the limited number of pharmacological treatments currently available. Interventions to address modifiable risk factors, including diet, body weight and physical activity and the management of associated comorbidities, remain the cornerstone of treatment for all patients. For patients with more advanced disease, addressing components of the metabolic syndrome, individual pharmacotherapy decisions and management for cirrhosis-related complications are available. ${ }^{32,65}$

The Cincinnati Children's Steatohepatitis Centre delivers a multidisciplinary programme of diet and exercise advice for paediatric patients with NAFLD. Patients meet with a gastroenterologist, nurse and dietitian every 3 months, with an initial 60-minute consultation to set individualized goals and 30-minute follow-up meetings to monitor progress and make changes to the intervention. Referrals are made to an intensive weight loss programme where needed. Data from 39 patients who attended multiple visits within 1 year of their initial presentation showed that at baseline all patients had obesity, $91 \%$ were insulin resistant and $54 \%$ had clinically significant dyslipidaemia At one-year follow up, levels of alanine aminotransferase (ALT) (-36 U/L), aspartate aminotransferase (AST) (-22 $\mathrm{U} / \mathrm{L})$, total cholesterol $(-11 \mathrm{mg} / \mathrm{dL})$ and low-density lipoproteins $(-9 \mathrm{mg} / \mathrm{dL})$ were all significantly lower $(\mathrm{p}<0.05)$, and $69 \%$ of patients had a decreased BMI. ${ }^{66}$

The NUTH care bundle includes a NAFLD management algorithm to support decision making regarding what assessments and services a patient requires. The bundle provides a short, structured checklist to support the delivery of services and appropriate recording of key information. The bundle aims to ensure that patients' needs are addressed comprehensively, from establishing the metabolic risk factors and liver fibrosis stage to delivery of lifestyle advice, setting of weight reduction targets and metabolic risk factor management. ${ }^{39}$ 
At the Oxford University Hospital metabolic hepatology clinic, lifestyle and medical interventions are provided with the aim of improving liver and cardiovascular-related health. Emphasis is placed on weight management and meaningful weight reduction in patients with overweight and obesity. Medications are provided for the management of cardiovascular risk and diabetes. Analysis of data from 165 patients followed from baseline to their latest visit (median 13.3 months between first and latest visit; median two follow-up visits per patient) showed a statistically significant reduction in median AST ( $-11 \mathrm{IU} / \mathrm{L} ; \mathrm{p}=0.001)$ and ALT $(-7 \mathrm{IU} / \mathrm{L} ; \mathrm{p}=<0.0001)$ levels and transient elastography $(-1.3$ $\mathrm{kPa} ; \mathrm{p}=0.0097){ }^{37}$

At the Birmingham NAFLD clinic, tailored dietary and lifestyle advice is provided with the aim of achieving monthly weight loss of 1-2 kg, with advice on glycaemic control also given to patients with T2DM. Between January and December 2010, 65 patients were diagnosed with NAFLD at the clinic, 55 of whom attended a second visit (median time between visits 98 days; IQR 70-182) with statistically significant reductions in median weight $(-0.8 \mathrm{~kg} ; \mathrm{p}=<0.05)$, BMI $(-0.38 ; \mathrm{P}=<0.05), \mathrm{ALT}(-$ 12.5; $\mathrm{P}=<0.001)$ and $y$-glutamyltransferase (GGT) $(-13.0 ; \mathrm{P}=<0.001)$ between . ${ }^{59}$

Patients referred to the NAFLD clinic at the Royal Free Hospital (Camden \& Islington) undergo a comprehensive hepatological consultation, cardiovascular risk assessment and dietetic counselling. Data for 273 patients attending the clinic showed that between baseline and the latest follow-up visit (median duration 18 months) statistically significant improvements were seen in ALT, AST, systolic and diastolic blood pressure and total cholesterol, and 142 (52\%) achieved weight loss during follow-up. ${ }^{67}$ For patients that remain in primary care, focus is placed on controlling metabolic syndrome, promoting weight loss and regularly assessing for advanced fibrosis. ${ }^{36}$ In the Nottingham model, patients visiting the nurse-led transient elastography clinic are provided with a brief lifestyle intervention that includes signposting to community services, including for weight management. ${ }^{35}$

At the Milton Keynes University Hospital metabolic clinic, services are provided to patients with HIV with metabolic complications who meet a pre-defined criterion. NAFLD is one of the seven conditions managed through the clinic, with patients having consultations with a metabolic specialist and a dietitian. ${ }^{68}$

In addition to the seven comprehensive MoCs, we identified two examples from conference proceedings. At a single community hepatology centre in Colorado, USA, patients with a confirmed NAFLD diagnosis are placed into nurse-led clinics and seen every 1-3 months to assess changes in anthropometrics and to discuss nutrition and mental health, with focus groups on diet and exercise being provided. ${ }^{69}$ In an integrated healthcare system in San Diego, USA, patients with vibrationcontrolled transient elastography $\geq 8 \mathrm{kPa}$ are referred to a hepatologist, whereas patients earlier in the disease spectrum are referred to a wellness centre for a weight management intervention and/or are enrolled in an education intervention. ${ }^{70}$

In addition to managing liver-related complications, five of the models explicitly addressed common comorbid conditions including CVD and type 2 diabetes, highlighting the importance of recognising the complex needs of patients with NAFLD when designing care models. Diet and lifestyle modification have a critical role in the prevention and treatment of NAFLD, and all of the models we identified incorporated some form of dietary intervention. Delivery of lifestyle interventions in clinical settings is more effective when driven by behavioural change approaches provided within a long-term comprehensive lifestyle modification programme ${ }^{71}$, rather than unsolicited advice. This approach requires the availability of clinical dietitians familiar with NAFLD and its comorbidities, and specific training for clinicians and healthcare providers to equip them with the necessary skills and resources to provide at least initial nutritional advice and to promote patients' motivation for lifestyle modification. ${ }^{72}$ Overall, the evidence supports the reduction of saturated fat, refined 
carbohydrates, and red and processed meats in patients with NAFLD. ${ }^{24}$ Specific diets have been shown to have some benefit in patients with NAFLD, namely the Mediterranean diet and the Dietary Approaches to Stop Hypertension (DASH). ${ }^{23,24}$

Patients with NAFLD require treatment strategies related to their position on the disease spectrum. Having clear guidance on treatments helps to facilitate efficient and effective linkages to care, based on an individual patient's needs. Interventions aimed at altering lifestyle-related risk factors, namely diet and physical activity, remain the cornerstone of treatment for all patients. With the expectation that NASH-specific pharmacological treatments will be available in the near future, clear guidance will also be needed on which patients can benefit from such treatments and how they will be able to access these.

\section{[H2] 4. Outline prevention actions in primary care and community services}

The majority of patients with NAFLD do not require intensive, specialist-led interventions to manage the hepatic component of the disease. Four of the models we identified specifically noted the role of primary care providers for patients not requiring specialized care. For patients with NAFL or earlystage fibrosis, the focus should be on preventing disease progression and the development or exacerbation of metabolic comorbidities. This aim can be achieved through a set of healthpromoting actions that address a range of risk factors associated with NAFLD, metabolic syndrome and other common non-communicable diseases, including diet and physical activity counselling as part of structured programmes. Monitoring of progression of the disease can be tailored according to risk profiles to maximise outcomes, in particular taking age at initial presentation into account..

Systems for monitoring liver disease progression in specific population groups and ensuring linkage to care are beneficial. The Nottingham, Camden \& Islington, North East England and Oxford care pathways all recommend repeat risk stratification of patients within 3-5 years if still indicated. ${ }^{35-38}$ Given the burden of NAFLD and the limited healthcare resources, a pragmatic approach to monitoring disease progress is likely needed, and such an approach could be guided by a patient's prognosis. Regular monitoring might be less beneficial and cost-effective in older patients with earlystage fibrosis where the risk of developing cirrhosis is considered low, whereas for younger patients more-regular monitoring to determine disease progression might be warranted.

Access to high-quality primary care preventive interventions is critical to reducing the burden of noncommunicable diseases and addressing the inherent inequalities associated with these diseases. ${ }^{73}$ With obesity, T2DM, CVD and NAFLD sharing several common risk factors, including poor diets and physical inactivity, ${ }^{74}$ there are opportunities for delivering public health and clinical interventions that collectively address these conditions. However, as of now little attention is being given to such strategies. Of 29 European countries surveyed in 2019, none had a strategy for diet and lifestyle interventions that mentioned NAFLD. ${ }^{28}$

Integrating services for non-communicable diseases within primary care presents numerous challenges, including overcoming the competing priorities and time constraints on general practitioners. For primary care interventions to be feasible, efficient and effective systems are needed for identifying patients who would benefit and then linking them to the relevant primary care or community services. Structured disease management programmes are likely to deliver more benefit then general advice. In this context, established management programmes for high-risk patient populations, for example patients with diabetes, can serve as examples. ${ }^{75}$ Integrating other health professionals into primary care systems, namely dieticians, should be considered. Decentralising the provision of care, including through community-based care models, can also be an effective approach. ${ }^{76}$ Adequate training and resourcing are key to implementation of effective programmes in primary care. Ensuring synergies between stakeholders with mutual goals is also key, 
and developing local communities of practice that go beyond healthcare providers to include other stakeholders such as community groups, businesses and sports bodies can be an effective approach. ${ }^{77}$

Liver health specialists will need to collaborate with primary care providers, public health experts and other disciplines - including non-communicable disease experts - to identify the package of interventions and to determine which patients will benefit from accessing these services. It will also be important to evaluate the effectiveness of these approaches, including the cost-effectiveness of early intervention in patients with NAFLD.

\section{[H1] Where should the services be provided?}

\section{[H2] 5. Articulate the roles of and interactions between primary and secondary care providers}

Given the differing clinical needs of patients with NAFLD, care is delivered across the healthcare system with services delivered by primary, secondary and tertiary care providers. Patients without advanced fibrosis can generally be managed in primary care, whereas those with advanced fibrosis and cirrhosis require more aggressive management led by specialists in secondary care, ${ }^{32,78}$ with a proportion of these requiring tertiary care, such as for transplant surgery. ${ }^{79,80}$

Although the distribution of services across a healthcare system will depend on the local context, fundamental to the implementation of a good MOC is a clear articulation of where different services will be provided and how patients will navigate between different parts of the health system. Building systems that enable close collaboration and effective communication between service providers, especially between primary and secondary care, is essential. This requirement reaffirms the need for collaborative approaches during the development of care pathways, as observed with the Nottingham, Oxford and Camden \& Islington examples. ${ }^{35-37}$

The Nottingham, NUTH, Oxford and Camden \& Islington models all outline the critical role of primary care providers, both in screening and risk stratification and the management of care for those without advanced disease..$^{35-37,39,67}$ Despite the critical role of primary care providers, the condition remains largely under-recognised in primary care settings, and primary care providers have limited knowledge of the disease and their role in managing it. ${ }^{19,81,82}$ The example from San Diego specifically incorporated education from primary care physicians, including creating awareness of high-risk population groups who might require screening. ${ }^{70}$

\section{[H2] 6. Service co-located for NAFLD and NASH comorbidities}

The co-location of screening services in strategic locations, such as diabetes clinics, can assist in the identification of previously undiagnosed NAFLD cases and ensure linkages to care. ${ }^{48,59}$ Analysis of referrals to the Birmingham NAFLD clinic showed that $28 \%$ came from secondary care settings, highlighting the importance of incorporating other secondary care disciplines within NAFLD care pathways. ${ }^{59}$ As previously noted, a lack of consensus remains among professional bodies on the effectiveness of systemic screening in high-risk populations, including those with diabetes. ${ }^{26,27}$ However, there is growing evidence of the cost-effectiveness of NAFLD screening in patients with T2DM and growing calls from experts to routinize screening in this group..$^{83}$

With NAFLD sharing a complex relationship with several highly prevalent metabolic diseases, including CVD and T2DM, and the growing evidence of bidirectional influences on the natural history of these comorbidities, there is a strong case for providing a comprehensive range of services tailored to patient needs. ${ }^{84}$ At the endocrinology clinic at a tertiary hospital in Sweden, patients with T2DM ( $n=91$ ) underwent a 4-day personalized treatment programme, which in addition to improving 
glycated haemoglobin levels also resulted in a reduction in liver steatosis and stiffness after three months. ${ }^{85}$ Evidence suggests that knowledge of NAFLD among patients with T2DM, including the association with metabolic conditions, is low, ${ }^{86}$ indicating the need for targeted approaches to increase awareness.

The co-location of services can also reduce the burden on patients by removing the need for multiple visits to different specialists, while also creating efficiencies within the health system. Several of the models we identified were multidisciplinary clinics that in addition to managing NAFLD provide services for other common comorbid conditions. The Camden \& Islington model provides comprehensive hepatological consultation and cardiovascular risk assessment, with patients seeing different clinical specialists on the same day. ${ }^{67}$ The 'multidisciplinary metabolic hepatology clinic' in Oxford aims to improve both liver-related and cardiovascular health, providing services for lifestyle modifications and medications for hypertension, dyslipidaemia and diabetes. ${ }^{37}$ At the Birmingham NAFLD clinic, a multidisciplinary team assess patients for diabetes and review current medications. ${ }^{59}$

Decisions about the co-location of services will be specific to the local content. In large urban settings, specialized clinics that provide a range of services that address the hepatic component of the disease and common comorbidities might be feasible and cost-effective, whereas in less densely populated areas such approaches might not be practicable. For certain services where a patient does not need to be physically present, virtual co-location can also be considered, for example multidisciplinary team consultations or dietary and lifestyle interventions delivered through teleconferencing ${ }^{87}$.

\section{[H1] Who should the services be provided by?}

\section{[H2] 7. Composition and structure of the multidisciplinary team}

The delivery of a comprehensive package of services for individuals with NAFLD requires the establishment of multidisciplinary teams. ${ }^{18}$ Table 1 shows the professionals involved in the delivery of care in each of the seven identified models. Five of the models included a hepatologist (71\%), two included a gastroenterologist (29\%) and one included a specialist in "metabolic medicine" (14\%). Five models included a dietician (71\%), two included an endocrinologist or diabetes physician (29\%), one a cardiovascular expert (14\%) and one an exercise physiotherapist (14\%).

Based on their experiences of developing the multidisciplinary NAFLD clinic in Birmingham, the authors suggest that inputs are required from hepatologists, diabetes specialist, weight loss experts, diabetes specialist nurses, dietitians and practitioners proficient in the use of non-invasive diagnostic tools. ${ }^{88}$ In all seven of the models nurses and allied health professionals had a central role, including in providing diagnostic services and delivering lifestyle interventions. At the metabolic clinic for individuals with HIV, NAFLD is only one of seven conditions being managed; in this setting the team is comprised of a metabolic medicine specialist and a dietician who liaise with the HIV consultant to discuss cases. Other professionals who might be engaged in the delivery of care for patients with NAFLD are psychologists and pharmacists.

The composition of the multidisciplinary teams will be guided by the specific aims of a clinic and the local health system context, including the available human and financial resources. Understanding the local health system barrier to the delivery of integrated, multidisciplinary MOCs - such as siloed ways of working - and developing active strategies to overcome these will be critical to success. Given the competing priorities for liver health specialists and general practitioners, 'NASH-nurse'-led care models might provide an effective way to deliver care at scale.

\section{[H1] How can these services be integrated, and coordination provided?}




\section{[H2] 8. Coordinating and integrating care across the healthcare system}

Actively engaging patients and considering their perspectives when designing care models is critical given that patient experiences reflect their perceptions around the quality of care they are receiving, ${ }^{89}$ and patient satisfaction is linked to better adherence and clinical outcomes. ${ }^{90}$

Developing patient-centric structures and systems that facilitate the coordination and integration of services delivered at different levels of the healthcare system (primary, secondary and tertiary) and by different specialities (for example, general practitioners, hepatology, endocrinology, cardiology and dietetics) is central to the development of successful NAFLD models of care. Patients and patient advocates (such as patient groups) should be actively engaged in the development of each aspect of care models, and patient-reported outcome data can inform continuous improvements to existing models. Efforts are needed to expand the number of tools that can be used to assess patient needs and outcomes in different healthcare settings. ${ }^{42}$

Five of the seven models we identified were multidisciplinary clinics that provide comprehensive services and care at one location. ${ }^{37,59,66-68}$ This 'one-stop shop' approach has numerous benefits for ensuring that care is coordinated and integrated, enabling patient needs to be holistically assessed and addressed. Importantly, the reduction in stigmatisation and discrimination in specialized clinics will enable patients to engage more actively in diagnostic and treatment decisions and empower them to manage their disease from an informed standpoint.

Health information technology provides opportunities for further improving the coordination and integration of services for patients with chronic disease and enabling greater levels of collaboration between patients and providers. ${ }^{91}$ An example comes from the Nottingham model, where the care pathway was accessed through an electronic system call the 'Integrated Clinical Environment', facilitating communication between the primary and secondary care providers. ${ }^{35}$

Considerations about how best to integrate and coordinate care will be highly contextualised to the specific healthcare system. Implementation research will have an important role in expanding the evidence base. In addition to expanding our understanding of what works for patient outcomes, we also need to establish the cost-effectiveness of different coordination and integration approaches in different healthcare settings, and how the information needs of different stakeholders' groups (for example, care providers, patients and patient groups, and payers) can be adequately met.

\section{[H1] Recommendations and conclusions}

Our review identified only seven examples of comprehensive models of care for NAFLD: six from the UK and one from the USA, highlighting the lack of attention given to this issue. We supplemented the seven examples with expert opinion and wider literature to develop a set of eight recommendations that are relevant for a broad range of settings and stakeholders (Box 2 ) .

The eight recommendations are not intended as a checklist, but rather as a framework to help guide practitioners and policymakers seeking to improve care for people with NAFLD. As such, they were structured in a way that aids their operational relevance, yet it is important to note that they are neither mutually exclusive nor chronological, but should be considered holistically. We acknowledge the limitations of the existing evidence and suggest that the recommendations be reviewed and updated periodically as we learn more about NAFLD MOCs, including the effect on clinical outcomes and the cost-effectiveness of different approaches. 
Nevertheless, given the increasing prevalence of NAFLD and the low percentage of diagnosed cases, health systems need to start reorienting to ensure that care can be delivered efficiently and effectively to address this progressive condition and reduce its wide-reaching health implications. The eight recommendations we set out herein contribute to filling the dearth of guidance on how best to address the gaps in care for patients with NAFLD. 


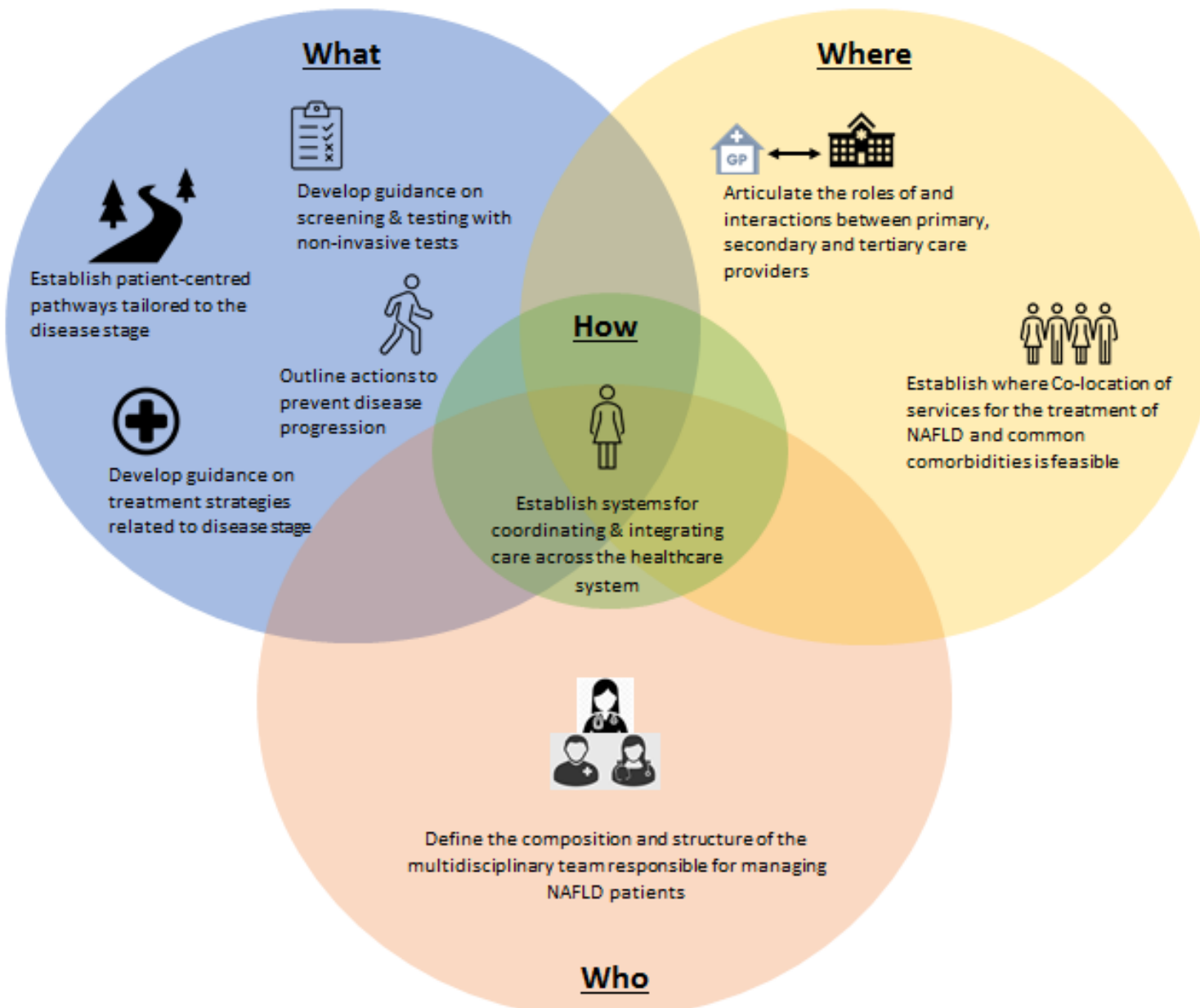

Figure 1: The road to comprehensive models of care for NAFLD. To achieve the best possible outcomes for patients with NAFLD, we need comprehensive care models that outline how patients are managed along the cascade of care, from diagnosis to treatment. This requires a clear understanding of what services are required, who should provide them, where they should be provided and how they will be integrated within healthcare systems. The figure highlights the importance of care pathways and early diagnosis as the first step in the care cascade. Primary care and secondary care providers have key roles in the identification of patients and linking them to appropriate care. Many patients can be managed in primary care, while those with advanced fibrosis and cirrhosis need specialist care delivered by a multidisciplinary team. Integration and coordination within different healthcare systems is critical, including effective communication between specialists, primary care providers and patients. 
1 Vos, T. et al. Global burden of 369 diseases and injuries in 204 countries and territories, 1990\&2013;2019: a systematic analysis for the Global Burden of Disease Study 2019. The Lancet 396, 1204-1222, doi:10.1016/S0140-6736(20)30925-9 (2020).

2 Younossi, Z. M. et al. Global epidemiology of nonalcoholic fatty liver disease-Meta-analytic assessment of prevalence, incidence, and outcomes. Hepatology 64, 73-84, doi:10.1002/hep.28431 (2016).

3 Ekstedt, M., Nasr, P. \& Kechagias, S. Natural History of NAFLD/NASH. Curr Hepatol Rep 16, 391-397, doi:10.1007/s11901-017-0378-2 (2017).

4 Calzadilla Bertot, L. \& Adams, L. A. The Natural Course of Non-Alcoholic Fatty Liver Disease. Int J Mol Sci 17, doi:10.3390/ijms17050774 (2016).

5 Estes, C. et al. Modeling NAFLD disease burden in China, France, Germany, Italy, Japan, Spain, United Kingdom, and United States for the period 2016-2030. Journal of Hepatology 69, 896-904 (2018).

6 Estes, C., Razavi, H., Loomba, R., Younossi, Z. \& Sanyal, A. J. Modeling the epidemic of nonalcoholic fatty liver disease demonstrates an exponential increase in burden of disease. Hepatology 67, 123-133 (2018).

7 Adams, L. A., Anstee, Q. M., Tilg, H. \& Targher, G. Non-alcoholic fatty liver disease and its relationship with cardiovascular disease and other extrahepatic diseases. Gut 66, 1138-1153, doi:10.1136/gutjnl-2017-313884 (2017).

8 Anstee, Q. M., Targher, G. \& Day, C. P. Progression of NAFLD to diabetes mellitus, cardiovascular disease or cirrhosis. Nat Rev Gastroenterol Hepatol 10, 330-344, doi:10.1038/nrgastro.2013.41 (2013).

9 Byrne, C. D. \& Targher, G. NAFLD: a multisystem disease. J Hepatol 62, S47-64, doi:10.1016/j.jhep.2014.12.012 (2015).

10 Angulo, P. et al. Liver Fibrosis, but no other histologic features, is asssociated with long-term outcomes of patients with nonalcoholic fatty liver disease. Gastroenterology 149, 389397.e310, doi:10.1053/j.gastro.2015.04.043 (2015).

11 Haflidadottir, S. et al. Long-term follow-up and liver-related death rate in patients with nonalcoholic and alcoholic related fatty liver disease. BMC Gastroenterol 14, 166, doi:10.1186/1471-230x-14-166 (2014).

12 Park, S. K., Seo, M. H., Shin, H. C. \& Ryoo, J. H. Clinical availability of nonalcoholic fatty liver disease as an early predictor of type 2 diabetes mellitus in Korean men: 5 -year prospective cohort study. Hepatology 57, 1378-1383, doi:10.1002/hep.26183 (2013).

13 Taylor, R. S. et al. Association Between Fibrosis Stage and Outcomes of Patients With Nonalcoholic Fatty Liver Disease: A Systematic Review and Meta-Analysis. Gastroenterology 158, 1611-1625 e1612, doi:10.1053/j.gastro.2020.01.043 (2020).

14 O'Hara, J. et al. Cost of non-alcoholic steatohepatitis in Europe and the USA: The GAIN study. JHEP Rep 2, 100142, doi:10.1016/j.jhepr.2020.100142 (2020).

15 Hagström, H. et al. Health Care Costs of Patients With Biopsy-Confirmed Nonalcoholic Fatty Liver Disease Are Nearly Twice Those of Matched Controls. Clin Gastroenterol Hepatol 18, 1592-1599.e1598, doi:10.1016/j.cgh.2019.10.023 (2020).

16 Younossi, Z. M. et al. The economic and clinical burden of nonalcoholic fatty liver disease in the United States and Europe. Hepatology 64, 1577-1586, doi:10.1002/hep.28785 (2016).

17 Huber, Y. et al. Health-related Quality of Life in Nonalcoholic Fatty Liver Disease Associates With Hepatic Inflammation. Clin Gastroenterol Hepatol 17, 2085-2092 e2081, doi:10.1016/j.cgh.2018.12.016 (2019).

18 Ruissen, M. M., Mak, A. L., Beuers, U., Tushuizen, M. E. \& Holleboom, A. G. Non-alcoholic fatty liver disease: a multidisciplinary approach towards a cardiometabolic liver disease. Eur J Endocrinol 183, R57-r73, doi:10.1530/eje-20-0065 (2020). 
19 Sanyal, A. J. Putting non-alcoholic fatty liver disease on the radar for primary care physicians: how well are we doing? BMC Med 16, 148, doi:10.1186/s12916-018-1149-9 (2018).

20 Araújo, A. R., Rosso, N., Bedogni, G., Tiribelli, C. \& Bellentani, S. Global epidemiology of nonalcoholic fatty liver disease/non-alcoholic steatohepatitis: What we need in the future. Liver International 38, 47-51, doi:10.1111/liv.13643 (2018).

21 Castera, L., Friedrich-Rust, M. \& Loomba, R. Noninvasive Assessment of Liver Disease in Patients With Nonalcoholic Fatty Liver Disease. Gastroenterology 156, 1264-1281.e1264, doi:10.1053/j.gastro.2018.12.036 (2019).

22 Neuschwander-Tetri, B. A. Therapeutic Landscape for NAFLD in 2020. Gastroenterology 158, 1984-1998.e1983, doi:10.1053/j.gastro.2020.01.051 (2020).

23 Berná, G. \& Romero-Gomez, M. The role of nutrition in non-alcoholic fatty liver disease: Pathophysiology and management. Liver Int 40 Suppl 1, 102-108, doi:10.1111/liv.14360 (2020).

24 Hydes, T. J., Ravi, S., Loomba, R. \& M, E. G. Evidence-based clinical advice for nutrition and dietary weight loss strategies for the management of NAFLD and NASH. Clin Mol Hepatol, doi:10.3350/cmh.2020.0067 (2020).

25 Ratziu, V. Non-pharmacological interventions in non-alcoholic fatty liver disease patients. Liver Int 37 Suppl 1, 90-96, doi:10.1111/liv.13311 (2017).

26 EASL-EASD-EASO Clinical Practice Guidelines for the management of non-alcoholic fatty liver disease. J Hepatol 64, 1388-1402, doi:10.1016/j.jhep.2015.11.004 (2016).

27 Chalasani, N. et al. The diagnosis and management of nonalcoholic fatty liver disease: Practice guidance from the American Association for the Study of Liver Diseases. Hepatology 67, 328-357, doi:10.1002/hep.29367 (2018).

28 Lazarus, J. V. et al. A cross-sectional study of the public health response to non-alcoholic fatty liver disease in Europe. J Hepatol 72, 14-24, doi:10.1016/j.jhep.2019.08.027 (2020).

29 Lazarus, J. V. et al. We know DAAs work, so now what? Simplifying models of care to enhance the hepatitis C cascade. Journal of Internal Medicine 286, 503-525, doi:10.1111/joim.12972 (2019).

30 Lazarus, J. V. et al. A systematic review of comprehensive models of care for NAFLD and NASH (626). AASLD The Liver Meeting. (2020).

31 Tsochatzis, E. A. \& Newsome, P. N. Non-alcoholic fatty liver disease and the interface between primary and secondary care. Lancet Gastroenterol Hepatol 3, 509-517, doi:10.1016/s2468-1253(18)30077-3 (2018).

32 Dyson, J. K., Anstee, Q. M. \& McPherson, S. Non-alcoholic fatty liver disease: a practical approach to treatment. Frontline Gastroenterol 5, 277-286, doi:10.1136/flgastro-2013100404 (2014).

33 Björkstrom, K., Stal, P., Hultcrantz, R. \& Hagstrom, H. Histologic Scores for Fat and Fibrosis Associate With Development of Type 2 Diabetes in Patients With Nonalcoholic Fatty Liver Disease. Clin Gastroenterol Hepatol 15, 1461-1468, doi:10.1016/j.cgh.2017.04.040 (2017).

34 Vanhaecht, K., De Witte, K. \& Sermeus, W. The impact of clinical pathways on the organisation of care processes PhD thesis, Katholieke Universiteit, (2007).

35 Chalmers, J. et al. The Development and Implementation of a Commissioned Pathway for the Identification and Stratification of Liver Disease in the Community. Frontline Gastroenterol 11, 86-92, doi:10.1136/flgastro-2019-101177 (2020).

36 Srivastava, A. et al. Prospective evaluation of a primary care referral pathway for patients with non-alcoholic fatty liver disease. J Hepatol 71, 371-378, doi:10.1016/j.jhep.2019.03.033 (2019).

37 Moolla, A. et al. A multidisciplinary approach to the management of NAFLD is associated with improvement in markers of liver and cardio-metabolic health. Frontline Gastroenterol 10, 337-346, doi:10.1136/flgastro-2018-101155 (2019). 
38 Hudson, M. \& Mcpherson, S. Liver Network Guidelines for the Management of Adults with Asymptomatic Liver Function Abnormalities On behalf of the North East \& North Cumbria Hepatology Network. (2020).

39 Neilson, L. J. et al. Implementation of a care bundle improves the management of patients with non-alcoholic fatty liver disease. Frontline Gastroenterology, flgastro-2020-101480, doi:10.1136/flgastro-2020-101480 (2021).

40 Shaheen, A. A. et al. Risk stratification of patients with nonalcoholic fatty liver disease using a case identification pathway in primary care: a cross-sectional study. CMAJ Open 8, E370e376, doi:10.9778/cmajo.20200009 (2020).

41 Dillon, J. F. et al. Intelligent liver function testing (iLFT): A trial of automated diagnosis and staging of liver disease in primary care. J Hepatol 71, 699-706, doi:10.1016/j.jhep.2019.05.033 (2019).

42 Doward, L. C. et al. Development of a Patient-Reported Outcome Measure for Non-Alcoholic Steatohepatitis (NASH-CHECK): Results of a Qualitative Study. Patient, doi:10.1007/s40271020-00485-w (2020).

43 Younossi, Z. M. \& Henry, L. Economic and Quality-of-Life Implications of Non-Alcoholic Fatty Liver Disease. Pharmacoeconomics 33, 1245-1253, doi:10.1007/s40273-015-0316-5 (2015).

44 Dyson, J. K., Anstee, Q. M. \& McPherson, S. Non-alcoholic fatty liver disease: a practical approach to diagnosis and staging. Frontline Gastroenterol 5, 211-218, doi:10.1136/flgastro2013-100403 (2014).

45 Wong, V. W. et al. Asia-Pacific Working Party on Non-alcoholic Fatty Liver Disease guidelines 2017-Part 1: Definition, risk factors and assessment. J Gastroenterol Hepatol 33, 70-85, doi:10.1111/jgh.13857 (2018).

46 American Diabetes Association. Comprehensive Medical Evaluation and Assessment of Comorbidities: Standards of Medical Care in Diabetes-2020. Diabetes Care 43, S37-S47, doi:10.2337/dc20-S004 (2020).

47 Taylor, R. S. et al. Association Between Fibrosis Stage and Outcomes of Patients With Nonalcoholic Fatty Liver Disease: A Systematic Review and Meta-Analysis. Gastroenterology 158, 1611-1625.e1612, doi:10.1053/j.gastro.2020.01.043 (2020).

48 Castera, L. Non-invasive tests for liver fibrosis in NAFLD: Creating pathways between primary healthcare and liver clinics. Liver Int 40 Suppl 1, 77-81, doi:10.1111/liv.14347 (2020).

49 Vali, Y. et al. Enhanced liver fibrosis test for the non-invasive diagnosis of fibrosis in patients with NAFLD: A systematic review and meta-analysis. J Hepatol 73, 252-262,

doi:10.1016/j.jhep.2020.03.036 (2020).

50 McPherson, S. et al. Age as a Confounding Factor for the Accurate Non-Invasive Diagnosis of Advanced NAFLD Fibrosis. Am J Gastroenterol 112, 740-751, doi:10.1038/ajg.2016.453 (2017).

51 Anstee, Q. M. et al. Noninvasive Tests Accurately Identify Advanced Fibrosis due to NASH: Baseline Data From the STELLAR Trials. Hepatology 70, 1521-1530, doi:10.1002/hep.30842 (2019).

52 Augustin, S. et al. Identification of Patients with Advanced Fibrosis Due to Nonalcoholic Fatty Liver Disease: Considerations for Best Practice. J Gastrointestin Liver Dis 29, 235-245, doi:10.15403/jgld-775 (2020).

53 Castera, L. Diagnosis of non-alcoholic fatty liver disease/non-alcoholic steatohepatitis: Noninvasive tests are enough. Liver Int 38 Suppl 1, 67-70, doi:10.1111/liv.13658 (2018).

54 Majumdar, A., Campos, S., Gurusamy, K., Pinzani, M. \& Tsochatzis, E. A. Defining the Minimum Acceptable Diagnostic Accuracy of Noninvasive Fibrosis Testing in Cirrhosis: A Decision Analytic Modeling Study. Hepatology 71, 627-642, doi:10.1002/hep.30846 (2020). Eslam, M. et al. A Sequential Algorithm Combining ADAPT and Liver Stiffness Can Stage Metabolic-Associated Fatty Liver Disease in Hospital-Based and Primary Care Patients. Am J Gastroenterol, doi:10.14309/ajg.0000000000001059 (2020). 
56 Bril, F. et al. Performance of Plasma Biomarkers and Diagnostic Panels for Nonalcoholic Steatohepatitis and Advanced Fibrosis in Patients With Type 2 Diabetes. Diabetes Care 43, 290-297, doi:10.2337/dc19-1071 (2020).

57 Hagström, H., Talbäck, M., Andreasson, A., Walldius, G. \& Hammar, N. Repeated FIB-4 measurements can help identify individuals at risk of severe liver disease. Journal of Hepatology, doi:10.1016/j.jhep.2020.06.007.

58 Oxford University Hospitals NHS Foundation Trust. in Investigating and Referring Incidental Findings of Abnormal Liver Tests Vol. v3.5 (Oxfordshire Clinical Comissioning Group, Online, 2018).

59 Armstrong, M. J. et al. Severe asymptomatic non-alcoholic fatty liver disease in routine diabetes care; a multi-disciplinary team approach to diagnosis and management. Qjm 107, 33-41, doi:10.1093/qjmed/hct198 (2014).

60 Crossan, C. et al. Referral pathways for patients with NAFLD based on non-invasive fibrosis tests: Diagnostic accuracy and cost analysis. Liver Int 39, 2052-2060, doi:10.1111/liv.14198 (2019).

61 Srivastava, A. et al. Cost-comparison analysis of FIB-4, ELF and fibroscan in community pathways for non-alcoholic fatty liver disease. BMC Gastroenterol 19, 122, doi:10.1186/s12876-019-1039-4 (2019).

62 Tanajewski, L. et al. Economic evaluation of a community-based diagnostic pathway to stratify adults for non-alcoholic fatty liver disease: a Markov model informed by a feasibility study. BMJ Open 7, e015659, doi:10.1136/bmjopen-2016-015659 (2017).

63 Standing, H. C. et al. GPs' experiences and perceptions of early detection of liver disease: a qualitative study in primary care. British Journal of General Practice 68, e743-e749, doi:10.3399/bjgp18X699377 (2018).

64 Wieland, A. C., Quallick, M., Truesdale, A., Mettler, P. \& Bambha, K. M. Identifying practice gaps to optimize medical care for patients with nonalcoholic fatty liver disease. Dig Dis Sci 58, 2809-2816, doi:10.1007/s10620-013-2740-8 (2013).

65 Muthiah, M. D. \& Sanyal, A. J. Current management of non-alcoholic steatohepatitis. Liver Int 40 Suppl 1, 89-95, doi:10.1111/liv.14355 (2020).

66 DeVore, S. et al. A multidisciplinary clinical program is effective in stabilizing BMI and reducing transaminase levels in pediatric patients with NAFLD. J Pediatr Gastroenterol Nutr 57, 119-123, doi:10.1097/MPG.0b013e318290d138 (2013).

67 Mantovani, A. et al. in EASL NAFLD Summit (Sevilla, Spain, 2019).

68 Ahmed, M. H., Woodward, C. \& Mital, D. Metabolic clinic for individuals with HIV/AIDS: a commitment and vision to the future of HIV services. Cardiovasc Endocrinol 6, 109-112, doi:10.1097/XCE.0000000000000128 (2017).

69 Hefner, A. M. et al. Integrating nurses in the management and care of patients with NAFLD: Better adherence and outcomes (413). EASL International Liver Congres. Vienna, Austria. (2019).

70 Patton, H., Stern, J., Moreno, M. \& Nyberg, L. A Novel Care Pathway for Nonalcoholic Fatty Liver Disease in a Large, Integrated Healthcare Delivery System (492). AASLD The Liver Meeting. San Francisco, USA. (2018).

71 Jensen, M. D. et al. 2013 AHA/ACC/TOS guideline for the management of overweight and obesity in adults: a report of the American College of Cardiology/American Heart Association Task Force on Practice Guidelines and The Obesity Society. Circulation 129, S102-138, doi:10.1161/01.cir.0000437739.71477.ee (2014).

72 Hallsworth, K., Avery, L. \& Trenell, M. I. Targeting Lifestyle Behavior Change in Adults with NAFLD During a 20-min Consultation: Summary of the Dietary and Exercise Literature. Curr Gastroenterol Rep 18, 11-11, doi:10.1007/s11894-016-0485-1 (2016).

73 Di Cesare, M. et al. Inequalities in non-communicable diseases and effective responses. Lancet 381, 585-597, doi:10.1016/s0140-6736(12)61851-0 (2013). 
74 Peters, R. et al. Common risk factors for major noncommunicable disease, a systematic overview of reviews and commentary: the implied potential for targeted risk reduction. Ther Adv Chronic Dis 10, 2040622319880392-2040622319880392, doi:10.1177/2040622319880392 (2019).

75 Fuchs, S., Henschke, C., Blümel, M. \& Busse, R. Disease management programs for type 2 diabetes in Germany: a systematic literature review evaluating effectiveness. Dtsch Arztebl Int 111, 453-463, doi:10.3238/arztebl.2014.0453 (2014).

76 Varghese, C. et al. Better health and wellbeing for billion more people: integrating noncommunicable diseases in primary care. BMJ 364, 1327, doi:10.1136/bmj.1327 (2019).

77 Lion, A. et al. Physical activity promotion in primary care: a Utopian quest? Health Promotion International 34, 877-886, doi:10.1093/heapro/day038 (2018).

78 Grgurevic, I. et al. Natural History of Nonalcoholic Fatty Liver Disease: Implications for Clinical Practice and an Individualized Approach. Can J Gastroenterol Hepatol 2020, 9181368, doi:10.1155/2020/9181368 (2020).

79 Haldar, D. et al. Outcomes of liver transplantation for non-alcoholic steatohepatitis: A European Liver Transplant Registry study. J Hepatol 71, 313-322, doi:10.1016/j.jhep.2019.04.011 (2019).

80 Terrault, N. A. \& Pageaux, G. P. A changing landscape of liver transplantation: King HCV is dethroned, ALD and NAFLD take over! J Hepatol 69, 767-768, doi:10.1016/j.jhep.2018.07.020 (2018).

81 Alexander, M. et al. Real-world data reveal a diagnostic gap in non-alcoholic fatty liver disease. BMC Medicine 16, 130, doi:10.1186/s12916-018-1103-x (2018).

82 Casler, K., Trees, K. \& Bosak, K. Providing Care for Fatty Liver Disease Patients: Primary Care Nurse Practitioners' Knowledge, Actions, and Preparedness. Gastroenterol Nurs 43, E184e189, doi:10.1097/sga.0000000000000487 (2020).

83 Noureddin, M. et al. Screening for Nonalcoholic Fatty Liver Disease in Persons with Type 2 Diabetes in the United States Is Cost-effective: A Comprehensive Cost-Utility Analysis. Gastroenterology 159, 1985-1987.e1984, doi:10.1053/j.gastro.2020.07.050 (2020).

84 Glass, L. M., Hunt, C. M., Fuchs, M. \& Su, G. L. Comorbidities and Nonalcoholic Fatty Liver Disease: The Chicken, the Egg, or Both? Fed Pract 36, 64-71 (2019).

85 Björkström, K. et al. A personalized treatment program in persons with type 2 diabetes is associated with a reduction in liver steatosis. Eur J Gastroenterol Hepatol, doi:10.1097/meg.0000000000001882 (2020).

86 Alemany-Pagès, M. et al. Insights from qualitative research on NAFLD awareness with a cohort of T2DM patients: time to go public with insulin resistance? BMC Public Health 20, 1142, doi:10.1186/s12889-020-09249-5 (2020).

87 Kelly, J. T., Reidlinger, D. P., Hoffmann, T. C. \& Campbell, K. L. Telehealth methods to deliver dietary interventions in adults with chronic disease: a systematic review and meta-analysis. The American Journal of Clinical Nutrition 104, 1693-1702, doi:10.3945/ajcn.116.136333 (2016).

88 Townsend, S. A. \& Newsome, P. N. The Role of a Dedicated Non-Alcoholic Fatty Liver Disease Clinic in 2016. Dig Dis 35, 371-376, doi:10.1159/000456589 (2017).

89 Wong, E. L. Y. et al. Patient experience and satisfaction with inpatient service: development of short form survey instrument measuring the core aspect of inpatient experience. PLOS One 10, e0122299-e0122299, doi:10.1371/journal.pone.0122299 (2015).

90 Martin, L. R., Williams, S. L., Haskard, K. B. \& Dimatteo, M. R. The challenge of patient adherence. Ther Clin Risk Manag 1, 189-199 (2005).

91 Dixon, B. E., Embi, P. J. \& Haggstrom, D. A. Information technologies that facilitate care coordination: provider and patient perspectives. Translational Behavioral Medicine 8, 522525, doi:10.1093/tbm/ibx086 (2018). 
92 Wilton Park. Consensus for Care Pathways for NAFLD/NASH. (2020).

<https://www.wiltonpark.org.uk/wp-content/uploads/2020/09/WP1736V1-Report.pdf>.

93 Gehrke, N. \& Schattenberg, J. M. Metabolic Inflammation-A Role for Hepatic Inflammatory Pathways as Drivers of Comorbidities in Nonalcoholic Fatty Liver Disease? Gastroenterology 158, 1929-1947 e1926, doi:10.1053/j.gastro.2020.02.020 (2020).

94 Younossi, Z. et al. Global Perspectives on Nonalcoholic Fatty Liver Disease and Nonalcoholic Steatohepatitis. Hepatology 69, 2672-2682, doi:10.1002/hep.30251 (2019).

95 Albhaisi, S., Chowdhury, A. \& Sanyal, A. J. Non-alcoholic fatty liver disease in lean individuals. JHEP reports : innovation in hepatology 1, 329-341, doi:10.1016/j.jhepr.2019.08.002 (2019).

96 Musso, G., Gambino, R., Cassader, M. \& Pagano, G. Meta-analysis: natural history of nonalcoholic fatty liver disease (NAFLD) and diagnostic accuracy of non-invasive tests for liver disease severity. Ann Med 43, 617-649, doi:10.3109/07853890.2010.518623 (2011).

97 Baratta, F. et al. Nonalcoholic Fatty Liver Disease and Fibrosis Associated With Increased Risk of Cardiovascular Events in a Prospective Study. Clinical Gastroenterology and Hepatology, doi:10.1016/j.cgh.2019.12.026 (2019).

98 Hagström, H. et al. Cardiovascular risk factors in non-alcoholic fatty liver disease. Liver Int 39, 197-204, doi:10.1111/liv.13973 (2019).

\section{Highlighted references}

- $\quad$ Ahmed, M. H., Woodward, C. \& Mital, D. Metabolic clinic for individuals with HIV/AIDS: a commitment and vision to the future of HIV services. Cardiovasc Endocrinol 6, 109-112, doi:10.1097/XCE.0000000000000128 (2017).

A novel approach to meet the needs of people living with HIV and metabolic conditions, including NAFLD, through a metabolic clinic.

- Armstrong, M. J. et al. Severe asymptomatic non-alcoholic fatty liver disease in routine diabetes care; a multi-disciplinary team approach to diagnosis and management. Qjm 107, 33-41, doi:10.1093/qjmed/hct198 (2014).

Detailing a non-invasive approach to identify asymptomatic NAFLD patients in diabetes care and deliver multi-disciplinary management.

- Chalmers, J. et al. The Development and Implementation of a Commissioned Pathway for the Identification and Stratification of Liver Disease in the Community. Frontline Gastroenterol 11, 86-92, doi:10.1136/flgastro-2019-101177 (2020).

A large care pathways for identification and risk stratification of liver disease in a community of cover 700,000 people.

- DeVore, S. et al. A multidisciplinary clinical program is effective in stabilizing BMI and reducing transaminase levels in pediatric patients with NAFLD. J Pediatr Gastroenterol Nutr 57, 119-123, doi:10.1097/MPG.0b013e318290d138 (2013).

A comprehenisve model of care for children with NAFLD.

- Lazarus, J. V. et al. A cross-sectional study of the public health response to non-alcoholic fatty liver disease in Europe. J Hepatol 72, 14-24, doi:10.1016/j.jhep.2019.08.027 (2020). Contributing the the dearth of research on national policies and guidelines for NAFLD and $\mathrm{NASH}$, it highlights the severe lack of attention the disease has been given in national health agendas.

- Moolla, A. et al. A multidisciplinary approach to the management of NAFLD is associated with improvement in markers of liver and cardio-metabolic health. Frontline Gastroenterol 10, 337-346, doi:10.1136/flgastro-2018-101155 (2019). 
Evaluation of a multidisciplinary team approach for the management of NAFLD and cardiovascular health.

- Srivastava, A. et al. Prospective evaluation of a primary care referral pathway for patients with non-alcoholic fatty liver disease. J Hepatol 71, 371-378, doi:10.1016/j.jhep.2019.03.033 (2019).

Results form a multi-year prospectve evaluation of a referal pathways for identifying and refreral of NAFLD within primary care

- Neilson, L. J. et al. Implementation of a care bundle improves the management of patients with non-alcoholic fatty liver disease. Frontline Gastroenterology, flgastro-2020-101480, doi:10.1136/flgastro-2020-101480 (2021).

Outlining a novel NAFLD 'care bundle' to standardise secondary care management and assessing the impact of implementation of the NAFLD care bundle.

\section{Acknowledgements}

The authors acknowledge the 27 participants of the Wilton Park-EASL International Liver Foundation virtual meeting "Consensus on Care Pathways for NAFLD/NASH" (16 June 2020) who reviewed an earlier unpublished draft of these recommendations. ${ }^{92}$ The authors thanks Marcela Villota Rivas (ISGlobal) for her contributions to the data search and analysis and for her input during the early drafting of the manuscript.

Author contributions

J.V.L. and H.E.M. researched data for article, made a substantial contribution to discussion of content, wrote the article, and reviewed/edited the manuscript before submission. All other authors made a substantial contribution to discussion of content, wrote the article, and reviewed/edited the manuscript before submission.

\section{Competing interests:}

The authors declare no competing interests.

Peer review information

Nature Reviews XXX thanks [Referee\#1 name], [Referee\#2 name] and the other, anonymous, reviewer(s) for their contribution to the peer review of this work. [Au: added as a placeholder for now]

Publisher's note

Springer Nature remains neutral with regard to jurisdictional claims in published maps and institutional affiliations.

\section{Review criteria}

We searched the peer-reviewed literature in PubMed/Medline and reviewed all abstracts for relevance based on pre-defined criteria. In addition, we conducted an auxiliary search of abstracts from the last two instalments of major hepatology/liver conferences. Conference abstracts were only accepted for inclusion in the main results if they were associated with a peer-reviewed paper; see Supplementary Information for details of the search string and review criteria.

Supplementary information

Supplementary information is available for this paper at https://doi.org/10.1038/s415XX-XXX-XXXX-X

\section{Key points}

- Nonalcoholic fatty liver disease (NAFLD) places a substantial burden on healthcare systems; however, little attention has been given to the management of patients with this disease within healthcare settings. 
- We analysed published example of models of care for NAFLD and developed a set of recommendations for healthcare providers and policymakers seeking to improve NAFLD care models and patient outcomes.

- The eight recommendations detail what services are required by patients, where the services should be delivered, who should provide them and how services should be coordinated within healthcare systems.

- These recommendations can contribute to filling the dearth of guidance on NAFLD models of care and help address the increasing need for the provision of best practice care for patients. 
Table 1: Summary of seven comprehensive models of care for NAFLD patients that outline what services are provided, where the services are provided, who provides the services and how these services are integrated and coordinated within the healthcare system

\begin{tabular}{|c|c|c|c|c|c|c|}
\hline Study & Where (setting) & What (services) & $\begin{array}{l}\text { Who } \\
\text { (providers) }\end{array}$ & $\begin{array}{l}\text { How (integration } \\
\text { approach) }\end{array}$ & $\begin{array}{l}\text { Evaluated } \\
\text { population }\end{array}$ & Outcomes \\
\hline Ahmed et al. $(2017)^{68}$ & $\begin{array}{l}\text { Metabolic clinic } \\
\text { at Milton Keynes } \\
\text { University } \\
\text { Hospital, UK }\end{array}$ & $\begin{array}{l}\text { Clinic provides services for the } \\
\text { management of diabetes, } \\
\text { dyslipidaemia, CVD, NAFLD, } \\
\text { obesity, hypogonadism, and } \\
\text { osteoporosis and low vitamin D. }\end{array}$ & $\begin{array}{l}\text { Metabolic } \\
\text { medicine } \\
\text { specialist, } \\
\text { infectious } \\
\text { disease } \\
\text { physician, and } \\
\text { dietitian }\end{array}$ & $\begin{array}{l}\text { Multidisciplinary } \\
\text { team within the } \\
\text { metabolic clinic }\end{array}$ & $\mathrm{N} / \mathrm{A}$ & $N / A$ \\
\hline $\begin{array}{l}\text { Armstrong et al. } \\
(2014)^{59}\end{array}$ & $\begin{array}{l}\text { NAFLD clinic at } \\
\text { Queen Elizabeth } \\
\text { University } \\
\text { Hospital, } \\
\text { Birmingham, UK }\end{array}$ & $\begin{array}{l}\text { Routine clinical assessment and } \\
\text { observations, full liver aetiology } \\
\text { screen and an abdominal } \\
\text { ultrasound scan. TE for patients } \\
\text { diagnosed with NAFLD. Ultrasound- } \\
\text { guided liver biopsy where required. } \\
\text { Diagnostic tests for type } 2 \text { diabetes. } \\
\text { Dietary and lifestyle assessment } \\
\text { and guidance. }\end{array}$ & $\begin{array}{l}\text { Hepatologists, } \\
\text { endocrinologist, } \\
\text { diabetes } \\
\text { specialist } \\
\text { nurses, } \\
\text { specialist } \\
\text { dietitian (with } \\
\text { an interest in } \\
\text { liver disease) } \\
\text { and rotating } \\
\text { clinic research } \\
\text { fellows }\end{array}$ & $\begin{array}{l}\text { Mutli-disciplinary } \\
\text { team within a NAFLD } \\
\text { clinic }\end{array}$ & $\begin{array}{l}95 \text { new } \\
\text { patient } \\
\text { referrals were } \\
\text { seen between } \\
1 \text { January } \\
2010 \text { and } 31 \\
\text { December } \\
2010\end{array}$ & $\begin{array}{l}65 / 95 \text { (68.4\%) patients } \\
\text { referred were newly } \\
\text { diagnosed with NAFLD. } \\
\text { During median follow-up } \\
\text { of } 98 \text { days, significant } \\
\text { reduction in weight and } \\
\text { BMI and significant } \\
\text { improvement in ALT, AST } \\
\text { and GGT were observed. }\end{array}$ \\
\hline $\begin{array}{l}\text { Chalmers et al. } \\
(2020)^{35}\end{array}$ & $\begin{array}{l}\text { Primary care } \\
\text { clinics and the TE } \\
\text { clinic at Queen's } \\
\text { Medical } \\
\text { Centre, } \\
\text { Nottingham } \\
\text { University } \\
\text { Hospitals, UK }\end{array}$ & $\begin{array}{l}\text { GPs: Liver disease risk assessment, } \\
\text { referral to the TE clinic and } \\
\text { hepatologist } \\
\text { TE clinic: NAFLD risk assessment } \\
\text { and TE (FibroScan, Echosens). Brief } \\
\text { lifestyle intervention including } \\
\text { signposting to local alcohol and } \\
\text { weight management services }\end{array}$ & $\begin{array}{l}\text { GPs, nurses and } \\
\text { healthcare } \\
\text { assistants } \\
\text { trained to } \\
\text { perform TE and } \\
\text { deliver a brief } \\
\text { lifestyle } \\
\text { intervention } \\
\text { Hepatologist } \\
\text { (referrals). }\end{array}$ & $\begin{array}{l}\text { An integrated } \\
\text { referral pathway } \\
\text { between primary } \\
\text { and secondary care, } \\
\text { linkages to local } \\
\text { services }\end{array}$ & $\begin{array}{l}\text { 968 patients } \\
\text { attending the } \\
\text { TE clinic } \\
\text { between } \\
\text { September } \\
2016 \text { and } \\
\text { August } 2017\end{array}$ & $\begin{array}{l}\text { 941/968 }(97.2 \%) \text { of } \\
\text { patients met one or } \\
\text { more of the referral } \\
\text { criteria. TE results } \\
\text { showed elevated liver } \\
\text { stiffness in } 222 / 968 \\
(22.9 \%) \text { patients, } 63 / 222 \\
\text { patients (38.2\%) with TE } \\
8-14.9 \mathrm{kPa} \text { and } 45 \\
(78.9 \%) \text { patients with TE }\end{array}$ \\
\hline
\end{tabular}




\begin{tabular}{|c|c|c|c|c|c|c|}
\hline & & & & & & $\begin{array}{l}\text { of } \geq 15 \mathrm{kPa} \text { were referred } \\
\text { to hepatology services. } \\
\text { Incremental cost- } \\
\text { effectiveness ratio for } \\
\text { the risk stratification } \\
\text { pathway of } £ 1895 \text { to } \\
£ 7032 / Q A L Y \text { with an } \\
85 \% \text { probability of cost- } \\
\text { effectiveness at the UK } \\
\text { willingness-to-pay } \\
\text { threshold of } £ 20 \\
\text { 000/QALY.62 }\end{array}$ \\
\hline DeVore et al. $(2013)^{66}$ & $\begin{array}{l}\text { CCSC, Cincinnati, } \\
\text { US }\end{array}$ & $\begin{array}{l}\text { Consultation with } \\
\text { gastroenterologist, nurse and } \\
\text { registered dietitian. Dietary and } \\
\text { exercise advice. Referral to } \\
\text { intensive weight management } \\
\text { program where required. } \\
\text { Evaluation of obesity-related co- } \\
\text { morbidities and referral to relevant } \\
\text { specialties. }\end{array}$ & $\begin{array}{l}\text { Gastroenterolog } \\
\text { ist, dietitian and } \\
\text { nurse }\end{array}$ & $\begin{array}{l}\text { A multidisciplinary } \\
\text { program of dietary } \\
\text { and exercise advice }\end{array}$ & $\begin{array}{l}108 \text { children } \\
\text { enrolled in } \\
\text { the } \\
\text { programme } \\
\text { between } \\
\text { November } \\
2007 \text { and } \\
\text { April } 2011\end{array}$ & $\begin{array}{l}\text { Analysis of } 39 \text { patients } \\
\text { who returned to clinic } \\
\text { within one year of their } \\
\text { initial visit showed mean } \\
\text { ALT, AST, total } \\
\text { cholesterol levels and } \\
\text { LDL levels were } \\
\text { significantly lower at one } \\
\text { year follow-up. }\end{array}$ \\
\hline $\begin{array}{l}\text { Mantovani et al. } \\
(2019)^{67}\end{array}$ & $\begin{array}{l}\text { Primary Care } \\
\text { Clinics and the } \\
\text { multidisciplinary } \\
\text { NAFLD clinic at } \\
\text { the Royal Free } \\
\text { Hospital, Camden } \\
\text { \& Islington, } \\
\text { London, UK }\end{array}$ & $\begin{array}{l}\text { GPs: Fibrosis assessment with FIB-4 } \\
\text { followed by ELF if FIB-4 } \\
\text { indeterminate. Management of } \\
\text { cardiovascular risks and diabetes. } \\
\text { NAFLD clinic: Comprehensive } \\
\text { hepatological consultation, } \\
\text { cardiovascular risk assessment and } \\
\text { dietetic counselling. } \\
\text { Anthropometric measurements, } \\
\text { blood pressure and blood tests } \\
\text { with lipid, hepatic, and glycaemic } \\
\text { profiles. }\end{array}$ & $\begin{array}{l}\text { Hepatologists, } \\
\text { dietitians, } \\
\text { cardiovascular } \\
\text { expert, } \\
\text { specialist nurse }\end{array}$ & $\begin{array}{l}\text { Multidisciplinary } \\
\text { clinic for } \\
\text { management of } \\
\text { NAFLD and } \\
\text { cardiovascular risk } \\
\text { factors }\end{array}$ & $\begin{array}{l}273 \text { patients } \\
\text { referred to a } \\
\text { multidisciplin } \\
\text { ary NAFLD } \\
\text { clinic (no } \\
\text { dates } \\
\text { reported) }\end{array}$ & $\begin{array}{l}\text { Over median follow-up } \\
\text { of } 18 \text { months statistically } \\
\text { significant } \\
\text { improvements were } \\
\text { observed in ALT, AST, } \\
\text { systolic and diastolic } \\
\text { blood pressure, total } \\
\text { cholesterol, LDL and } \\
\text { glycated haemoglobin in } \\
\text { diabetic patients. } \\
\text { Sequential use of NITs } \\
\text { lowered secondary care } \\
\text { referral rates, with } 90 \%\end{array}$ \\
\hline
\end{tabular}




\begin{tabular}{|c|c|c|c|c|c|c|}
\hline & & & & & & $\begin{array}{l}\text { of patients managed in } \\
\text { primary care and cost } \\
\text { savings of over } 40 \%{ }^{60}\end{array}$ \\
\hline Moolla et al. $(2019)^{37}$ & $\begin{array}{l}\text { Primary care } \\
\text { clinics and Oxford } \\
\text { University } \\
\text { Hospitals } \\
\text { metabolic } \\
\text { hepatology clinic, } \\
\text { Oxfordshire, UK }\end{array}$ & $\begin{array}{l}\text { Primary care: Risk-stratification } \\
\text { with the NAFLD fibrosis score } \\
\text { Metabolic hepatology clinic: TE } \\
\text { (FibroScan) medical consultation; } \\
\text { where clinically appropriate blood } \\
\text { testing, imaging, liver biopsy and } \\
\text { screening for hepatocellular } \\
\text { carcinoma. Lifestyle and medical } \\
\text { interventions. }\end{array}$ & $\begin{array}{l}\text { Hepatologists, } \\
\text { diabetologists/ } \\
\text { metabolic } \\
\text { physicians and } \\
\text { specialist nurses }\end{array}$ & $\begin{array}{l}\text { Local risk- } \\
\text { stratification and } \\
\text { referral pathways, } \\
\text { multidisciplinary } \\
\text { clinic, linkages to } \\
\text { community services }\end{array}$ & $\begin{array}{l}165 \text { patients } \\
\text { managed } \\
\text { through the } \\
\text { clinic } \\
\text { between } \\
\text { March } 2014 \\
\text { and May } \\
2017\end{array}$ & $\begin{array}{l}\text { During a median follow } \\
\text { up of } 13.3 \text { months } \\
\text { median values for ALT, } \\
\text { AST, glycated } \\
\text { haemoglobin, liver TE } \\
\text { and weight reduced } \\
\text { significantly. } \\
\text { In patients with poorly } \\
\text { managed type } 2 \text { diabetes } \\
\text { mellitus the incremental } \\
\text { cost-effectiveness ratio } \\
\text { cost per QALY } f 6.1 \mathrm{k} \\
\text { (95\% Cl } £ 0.3 \mathrm{k} \text { to } f 59.3 \mathrm{k} \text { ) } \\
\text { with } 91 \% \text { of model } \\
\text { bootstraps runs falling } \\
\text { below a cost per QALY } \\
\text { threshold of } £ 20000\end{array}$ \\
\hline
\end{tabular}




\begin{tabular}{|c|c|c|c|c|c|c|}
\hline Neilson et al. $(2021)^{39}$ & $\begin{array}{l}\text { Specialist NAFLD } \\
\text { clinic and general } \\
\text { hepatology clinics } \\
\text { in the Newcastle } \\
\text { upon Tyne } \\
\text { Hospitals NHS } \\
\text { Foundation } \\
\text { Trust (NUTH), } \\
\text { Newcastle, UK }\end{array}$ & $\begin{array}{l}\text { Assessment of anthropometry, } \\
\text { metabolic risk factors and liver } \\
\text { fibrosis stage and provision of } \\
\text { lifestyle advice and weight } \\
\text { reduction targets, metabolic risk } \\
\text { factor management and specific } \\
\text { NAFLD treatment. }\end{array}$ & $\begin{array}{l}\text { Hepatologists, } \\
\text { gastroenterolog } \\
\text { ists, specialist } \\
\text { dietician and } \\
\text { exercise } \\
\text { physiotherapist. }\end{array}$ & $\begin{array}{l}\text { Care bundle check } \\
\text { list and NAFLD } \\
\text { management } \\
\text { algorithm to guide } \\
\text { decision making and } \\
\text { care }\end{array}$ & $\begin{array}{l}50 \\
\text { consecutive } \\
\text { patients } \\
\text { attending } \\
\text { hepatology } \\
\text { clinics } \\
\text { following } \\
\text { implementati } \\
\text { on of the care } \\
\text { bundle }\end{array}$ & $\begin{array}{l}\text { Audit of } 50 \text { consecutives } \\
\text { patients with NAFLD } \\
\text { attending four NUTH } \\
\text { hepatology clinics } \\
\text { showed that the care } \\
\text { bundle resulted in } \\
\text { substantially } \\
\text { better documentation } \\
\text { and implementation of } \\
\text { several aspects of } \\
\text { patient management }\end{array}$ \\
\hline
\end{tabular}

CVD, cardiovascular disease; NAFLD, nonalcoholic fatty liver disease; ALT, alanine aminotransferase; AST, aspartate aminotransferase; ELF, enhanced liver fibrosis; FIB-4, Fibrosis-4; GGT, $\gamma$-glutamyl transferase; TE, transient elastography; GP, general practitioner; CCSC, Cincinnati Children's Steatohepatitis Centre; LDL, low-density lipoprotein. 
Table 2: Non-invasive tests used for the risk stratification of patients in NAFLD models of care and cut-offs for referral between primary and secondary care

\begin{tabular}{|c|c|c|c|c|}
\hline Model of care & NIT used & $\begin{array}{l}\text { Setting or } \\
\text { hospital }\end{array}$ & Cut-offs & Action \\
\hline \multirow{6}{*}{ Nottinghamshire 35} & $\begin{array}{l}\text { AST:ALT } \\
\text { ratio }\end{array}$ & \multirow{3}{*}{ General practice } & $\geq 0.8$ & GP refers to TE clinic \\
\hline & $\begin{array}{l}\text { Fatty liver } \\
\text { index }\end{array}$ & & $\geq 60$ & GP refers to TE clinic \\
\hline & Ultrasound & & Evidence of NAFLD & GP refers to TE clinic \\
\hline & \multirow{3}{*}{$\begin{array}{l}\text { TE } \\
\text { (FibroScan, } \\
\text { Echosens) }\end{array}$} & \multirow{3}{*}{$\begin{array}{l}\text { Nurse-led TE } \\
\text { clinic at a } \\
\text { secondary } \\
\text { hospital }\end{array}$} & $<8 \mathrm{kPa}$ & $\begin{array}{l}\text { Repeat TE in } 5 \text { years if } \\
\text { still indicated }\end{array}$ \\
\hline & & & $8-14.9 \mathrm{kPa}$ & $\begin{array}{l}\text { GP to consider referral } \\
\text { to hepatology services, } \\
\text { if not referred repeat TE } \\
\text { in } 3 \text { years if still } \\
\text { indicated }\end{array}$ \\
\hline & & & $\geq 15 \mathrm{kPa}$ & $\begin{array}{l}\text { GP advised to refer to } \\
\text { hepatology service }\end{array}$ \\
\hline \multirow{4}{*}{ Oxfordshire*37 } & NFS & Primary care & $\begin{array}{l}\geq-1.445-<0.676 \\
\text { (intermediate risk) } \\
\geq 0.676 \text { (high-risk) }\end{array}$ & $\begin{array}{l}\text { Refer to metabolic } \\
\text { hepatology clinic }\end{array}$ \\
\hline & $\begin{array}{l}\text { TE } \\
\text { (FibroScan) }\end{array}$ & \multirow{3}{*}{$\begin{array}{l}\text { Metabolic } \\
\text { hepatology } \\
\text { clinic }\end{array}$} & $<8 \mathrm{kPa}$ & \multirow{3}{*}{$\begin{array}{l}\text { Considered for } \\
\text { discharge from clinic } \\
\text { Recommended for } \\
\text { repeat risk stratification } \\
\text { in } 3 \text { years }\end{array}$} \\
\hline & NFS & & $<1.445$ (low-risk) & \\
\hline & $\begin{array}{l}\text { Fibrosis-4 } \\
\text { score }\end{array}$ & & <1.45 (low-risk) & \\
\hline \multirow{5}{*}{$\begin{array}{l}\text { Camden \& } \\
\text { Islington }{ }^{36}\end{array}$} & \multirow{3}{*}{$\begin{array}{l}\text { Fibrosis-4 } \\
\text { score }\end{array}$} & \multirow{5}{*}{ Primary care } & $<1.3$ & Manage in primary care \\
\hline & & & $1.3-3.25$ & Perform ELF test \\
\hline & & & $>3.25$ & Refer to hepatology \\
\hline & \multirow[b]{2}{*}{ ELF test } & & $<9.5$ & Manage in primary care \\
\hline & & & $>9.5$ & Refer to hepatology \\
\hline \multirow{3}{*}{$\begin{array}{l}\text { Newcastle upon } \\
\text { Tyne Hospitals } \\
\text { NHS Foundation } \\
\text { Trust (NUTH) }\end{array}$} & \multirow{2}{*}{$\begin{array}{l}\text { Fibrosis-4 } \\
\text { score }\end{array}$} & \multirow{2}{*}{ Primary care } & $\begin{array}{l}<1.3 \text { (for }<65 \text { year olds) } \\
<2.0 \text { (for } \geq 65 \text { year olds) }\end{array}$ & $\begin{array}{l}\text { Manage in primary } \\
\text { care. Reassess FIB-4 / } \\
\text { TE in } 3 \text { years }\end{array}$ \\
\hline & & & $\begin{array}{l}>1.3 \text { (for }<65 \text { year olds) } \\
>2.0 \text { (for } \geq 65 \text { year olds) }\end{array}$ & $\begin{array}{l}\text { Refer to secondary care } \\
\text { for TE }\end{array}$ \\
\hline & TE & Secondary care & $<8 \mathrm{kPa}$ & $\begin{array}{l}\text { Manage in primary } \\
\text { care. Reassess FIB- } 4 \text { and } \\
\text { TE in } 3 \text { years }\end{array}$ \\
\hline
\end{tabular}




\begin{tabular}{|l|l|l|l|}
\hline & & $>8 \mathrm{kPa}$ & NAFLD directed therapy \\
\hline
\end{tabular}

NIT, non-invasive test; AST, aspartate aminotransferase; ALT, alanine aminotransferase; GP, general practitioner; NAFLD, nonalcoholic fatty liver disease; TE, transient elastography; NFS, NAFLD fibrosis score; ELF, enhanced liver fibrosis. *The Oxfordshire pathway was updated in 2017 incorporating the ELF test in place of the NFS. ${ }^{58}$

\section{Box 1: Understanding the association between NAFLD, metabolic syndrome and common comorbidities}

The association between nonalcoholic fatty liver disease (NAFLD) and other chronic conditions is thought to be mediated, in part, by metabolic inflammation arising in the liver. ${ }^{93}$ NAFLD is strongly associated with obesity, with the prevalence increasing proportionally with increases in body mass index, ${ }^{94}$ although the disease also occurs in lean individuals, especially in Asian populations ${ }^{95}$ In the majority of patients, NAFLD emerges in the context of metabolic syndrome, with insulin resistance being the common pathophysiological mechanism. ${ }^{8}$ NAFLD shares a bidirectional relationship with metabolic syndrome, worsening insulin resistance and predisposing for atherogenic dyslipidaemia. ${ }^{8}$ The prevalence of NAFLD is higher in patients with type 2 diabetes mellitus (T2DM) than in the general population, while the incidence of T2DM is about twofold higher in patients with NAFLD. 8,12,33,96 Furthermore, several studies and meta-analyses have shown an increased risk of cardiovascular disease (CVD) in people with NAFLD. ${ }^{7-9}$ There is some evidence that the risk of a cardiovascular event increases with fibrosis stage; ${ }^{13,97}$ however, other studies have shown no independent association between histological markers and the risk of a CVD event. ${ }^{98}$

Box 2: Eight recommendations for developing comprehensive models of care for NAFLD and NASH [H1] What services should be provided?

1. Establish clearly defined care pathways that are tailored to assessing the stage of disease, the presence of comorbidities and the optimal health outcome for the patient.

2. Develop guidance on screening and testing with non-invasive tests.

3. Develop guidance on treatment strategies for patients, related to their disease stage.

4. Outline actions for preventing disease progression in primary care for patients with early-stage disease not requiring specialist hepatology care.

[H1] Where should these services be provided?

5. Articulate and define the roles and interactions between primary, secondary and tertiary care providers.

6. Establish where services for NAFLD can be co-located with services for the treatment of common comorbidities.

[H1] Who should these services be provided by?

7. Define the composition and structure of the multidisciplinary team responsible for managing patients.

[H1] How can these services be integrated, and coordination provided?

8. Establish effective systems for coordinating and integrating care across a healthcare system. 